\title{
REPRESENTACIONES SOBRE EL EJERCICIO DE LA DOCENCIA EN CONTEXTOS DE VULNERABILIDAD DE PROFESORES DE CIENCIAS SOCIALES EN PRÁCTICA
}

\author{
Gerardo Ignacio SÁNCHEZ SÁNCHEZ ${ }^{1}$ \\ Simón Hernán DÍAZ MÉNDEZ ${ }^{2}$ \\ Alex Ignacio FUENTES TORO ${ }^{3}$ \\ José Baltazar OSORIO CORREA ${ }^{4}$
}

\begin{abstract}
Resumen
El artículo aborda los procesos de práctica profesional de estudiantes de pedagogía de nivel medio en escenarios de vulnerabilidad. Mediante un enfoque cualitativo sustentando en entrevista y análisis de contenido, se concluye una representación de la docencia caracterizada por la multiplicidad de tareas que supone el rol docente; la complejidad insospechada de la tarea en estos contextos; la implicación personal y el posicionamiento ético que les demanda.
\end{abstract}

Palabras clave: vulnerabilidad, representaciones, docencia, práctica, Chile

\begin{abstract}
The following article discusses the history teachers' professional practicum process of mid-level in vulnerability scenarios. Through a qualitative approach based on an interview and content analysis, it is concluded a representation of teaching characterized by the multiplicity of tasks which is the teacher's role; the unexpected complexity of the task in these contexts; the personal involvement and the ethical position that demands them.
\end{abstract}

Keyword: vulnerability, representations, teaching, practice, Chile

\section{Résumé}

L'article suivant traite du processus de stage professionnel des professeurs d'histoire de niveau intermédiaire dans les scénarios de vulnérabilité. Par une approche qualitative basée sur une interview et une analyse de contenu, on conclut une représentation de l'enseignement caractérisé

\footnotetext{
${ }^{1}$ Doctor en Ciencias de la Educación. Académico adscrito al Departamento de Formación Inicial Escolar de la Facultad de Educación, de la de Universidad Católica del Maule. Chile. Plan de Mejoramiento UCM1310 de Formación Inicial de Profesores / gsanchez@ucm.c

${ }^{2}$ Profesor de Historia, Geografía y Ciencias Sociales. Licenciado en Educación

${ }^{3}$ Profesor de Historia, Geografía y Ciencias Sociales. Licenciado en Educación

${ }^{4}$ Profesor de Historia, Geografía y Ciencias Sociales. Licenciado en Educación

Fecha de recepción del artículo: Agosto 2016

Fecha de evaluación: Abril 2017
} 
par la multiplicité des tâches qui est le rôle de l'enseignant; La complexité inattendue de la tâche dans ces contextes; L'implication personnelle et la position éthique qui les exige

Mots-clés: vulnérabilité, représentations, enseignement, pratique, Chile

\title{
INTRODUCCIÓN Y REFERENTES TEÓRICOS
}

Las prácticas docentes, han sido objeto de fuertes críticas en el último tiempo, desde la academia, desde los contextos escolares, como también desde la propia sociedad, ello, debido a los bajos resultados de desempeño de los profesores en formación y el diagnóstico de las deficientes prácticas de enseñanza observadas y registradas durante largo tiempo al interior de las escuelas (Cisternas, 2011; Labra, 2011; Latorre, 2006; Ávalos, 2003).

La práctica docente de acuerdo con Ávalos (2003) se entendería como:

\begin{abstract}
El eje que articula todas las actividades curriculares de la formación docente, de la teoría y de la práctica. Su objetivo es permitir la aproximación gradual de los estudiantes al trabajo profesional, y al mismo tiempo facilitarles la construcción e internalización del rol docente. En forma más precisa, su finalidad es facilitar el proceso por el cual los futuros profesores construyen conocimiento pedagógico, desarrollan en forma personal teoría y práctica de la enseñanza y el aprendizaje y, sobre todo, aprenden a enseñar. Se postula que del modo cómo se organicen las experiencias de práctica dependerá el grado en que cada futuro profesor o profesora precise su rol profesional en el contexto de la comunidad, escuela y aula, aprenda a diagnosticar los problemas propios de esa situación y a buscar y poner a prueba soluciones (p. 109)
\end{abstract}

Las prácticas constituyen ocasiones de inmersión a diferentes niveles de profundidad en situaciones o contextos característicos de la profesión a desempeñar. Dotadas de un fuerte criterio de realidad y orientadas al aprendizaje profesional, permiten al estudiante aproximarse a un mundo diferente, que les plantea los problemas de la profesión de forma integrada. Esta acción se encuentra sostenida en un cuerpo teórico de conocimientos y requiere de un periodo de formación académica. Proporciona un saber que permite encaminar a los estudiantes hacia la deliberación para intervenir profesionalmente en la compleja vida del aula y de la escuela (Sayago, 2006).

Entendiendo su complejidad, la práctica de la docencia es una práctica técnica de competencias conductuales; una práctica intelectual de maestría cognitiva y cuidadosa reflexión; una práctica moral de responsabilidad social y personal, y juicio ético; y ante todo, una práctica emocional de apasionar y comprometer (Hargreaves, et al: 2009). De acuerdo con Imbernón (2001), supone un proceso que trasciende el ámbito meramente técnico para alcanzar el ámbito personal, profesional y social.

El período de práctica se podría entender como una transición, como el período en que los alumnos tienen que llevar a cabo tres transiciones: de la universidad a la escuela; de alumno a profesor y de la teoría a la práctica (Contreras, 1987). Un cambio de lugar, un cambio de rol y un cambio en el modo de utilizar el conocimiento y las destrezas necesarias.

El análisis de los procesos de práctica, permite reconocer la vigencia y el mantenimiento de lógicas dicotómicas en la formación de profesores: la tensión entre conocimiento teórico v/s conocimiento práctico; espacio universitario v/s espacio escolar como medio de aprendizaje y académico v/s profesor del medio escolar como agente formativo, en suma lo que Schön (1987, 1998, 2010) llamó como racionalidad técnica, o lo que Day (1999) denominó concepción aditiva, o lo que Russell y Korthagen (2006) llaman modelo de aplicación de la teoría. 
Como consecuencia de esa racionalidad, concepción o modelo, una gran cantidad de estudios ponen de manifiesto la inseguridad de los practicantes respecto a sus conocimientos o saberes al instante en que estos salen de las aulas universitarias y comienzan a conocer diferentes contextos en los cuales han de obrar con sus futuros estudiantes. En este sentido, Tardif (2004) señala que las necesidades de los estudiantes en práctica profesional, se conjugan una vez que los futuros docentes hacen contacto con la realidad dinámica del aula en contextos diferentes y es aquí donde deben movilizar saberes de diversa naturaleza, no sólo profesionales, sino también personales e idiosincráticos, "comprendiendo que en algunos este descubrimiento provoca el rechazo puro y simple de su formación anterior o el convencimiento de que el docente es el único responsable de su éxito (p. 39)

En ocasiones, quienes viven este proceso, suelen responsabilizar a la institución formadora en el caso de no saber obrar con el tipo de alumnos y con las culturas presentes en los establecimientos, desarrollando una actuación esencialmente aplicacionista y transmisiva, atribuyendo a la práctica, el papel de experiencias sostenidas en comportamientos reproductores de esquemas y rutinas docentes (Sayago, 2006)

Dado lo anterior, surge la necesidad de concebir las prácticas en un sentido más amplio, tomando en consideración los diversos aspectos y complejidades propias que debe sortear el practicante al momento de relacionarse en y con la Escuela. Recordemos que enfrenta la inserción al aula sometido a la presión de múltiples y simultáneas demandas del docente tutor de la universidad, el docente guía del establecimiento y las particularidades del grupo de estudiantes con el que le corresponde actuar.

Es preciso entender que esta práctica y el trabajo docente mismo responde a lógicas más bien deliberativas caracterizadas por: la multiplicidad de tareas que supone el rol docente; la variedad de contextos en que estas tareas pueden desempeñarse; la complejidad del acto pedagógico; su inmediatez; la indeterminación de las situaciones que se suscitan en el curso del proceso de trabajo docente; y la implicación personal y el posicionamiento ético que supone la tarea docente (Davini, 1995)

Con una práctica que no es reductible a un conjunto de dispositivos técnicos; pero tampoco a una sorpresa permanente, sino más bien entendida en la lógica de certeza situada de la que nos habla Hargreaves, en un sistema que permita recuperar el conocimiento construido, ponderarlo a la luz de la situación, dar lugar a las acomodaciones necesarias, generar alternativas y reconstruirlo todo en un nivel de reflexión que haga de la acción concreta, ocasión para la construcción de un nuevo sabe.

Práctica que debe responder a las demandas de las actuales sociedades, postmodernas y globalizadas, en las que es posible distinguir por lo menos dos finalidades de la educación. Puede ser descrita como el proceso que busca el despliegue de la propia personalidad y de las capacidades de los estudiantes, de modo que puedan comprender el mundo y obrar en él, con creciente autonomía y responsabilidad personal, construyendo un proyecto personal de vida que dé sentido a su existencia (Falabella, y Garcia-Huidobro, 2013, p.14) No olvidemos que el informe Delors (1996) de la UNESCO desglosa el desarrollo de la persona en cuatro adquisiciones: aprender a ser, aprender a conocer, aprender a hacer y aprender a vivir con otros.

Complementando la mirada anterior, está aquella finalidad que suele subrayar su cometido sociopolítico, vinculada a su potencial para formar a los futuros ciudadanos y dotarlos de los conocimientos y valores, actitudes y formas de comportamiento necesarios para vivir en sociedad y para hacer vivir a la sociedad.

En la concreción de ambas finalidades, la consecuencia final es la transformación de la enseñanza en una tarea que compromete de manera sustancial a la persona, con una experiencia que puede resultar altamente gratificante, pero también constituir fuente de crisis y amenaza permanente, 
sea por las competencias que se requieren o por las condiciones materiales y simbólicas en que éstas son movilizadas (Tenti, 2007)

En esta perspectiva, se requiere que los actores que forman parte del sistema educativo, especialmente los profesores, se encuentren en una constante reflexión frente a los futuros desafíos de un mundo globalizado, configurándose, así, como actores claves en un escenario complejo y de constante dinamismo.

Bajo esta lógica, la Formación Inicial de los docentes, se ha configurado a partir de un discurso reflexivo, en donde los profesionales de la educación, mediante sus saberes, estrategias y su experiencia, deben responder a diversos contextos en concomitancia con ello, Marcelo (2001), sostiene que el conocimiento base, entregado en las instituciones universitarias, no puede limitarse a la transmisión unidireccional de un conocimiento técnico y formal, sino que además debe asumir otros aspectos de carácter reflexivo, relacional, ético y colegial. Sin embargo, la estructuración y ejecución de muchos programas de pedagogía no coincide con lo señalado en la teoría, no existiendo la coherencia y equilibrio requerido y muchas veces marginando el papel de la práctica en la formación de los profesores. En este sentido, Paquay (2010) señala que:

Una formación práctica debe acercarse no sólo a la práctica y al saber práctico de un maestro experimentado sino a la propia práctica de los aprendices de maestros; esto presupone que en las estrategias generales de formación debemos conceder un espacio cada vez más grande a la expresión de dichas prácticas (pág. 166)

Necesitamos una formación en sintonía con la práctica. En caso contrario, la formación se torna un escenario incierto e impreciso, donde no es posible develar a ciencia exacta cómo se desempeña el docente o cuáles son los conocimientos, las estrategias que logra movilizar o finalmente, cuáles son las limitaciones que puede encontrar al momento de desenvolverse en diversos escenarios, tema este último cada vez más relevante dado el contexto de vulnerabilidad en que tiene lugar la docencia. En Chile el concepto de establecimiento vulnerable, está asociado principalmente a aquellos centros en donde la cobertura y matrícula se vincula con una población de un nivel socioeconómico bajo: la mayoría de los estudiantes requiere de recursos económicos del Estado para poder estudiar y se hallan insertos en un creciente marco de vulnerabilidad social.

En esas coordenadas, la docencia y la formación inicial se constituyen en un punto controversial de análisis y de estudio. La presente investigación pretende abordar la problemática que experimentan estudiantes de pedagogía media al enfrentar su ejercicio profesional en contextos de vulnerabilidad de los establecimientos educacionales donde se insertan. Se precisan las representaciones acerca de la tarea, las estrategias que despliegan y las limitaciones que enfrentan en estos escenarios de vulnerabilidad.

\section{OBJETIVOS}

La investigación pretende dar respuesta a la siguiente pregunta de investigación:

¿Cuál es la percepción de los profesores en formación respecto al ejercicio de la docencia en establecimientos escolares vulnerables? A partir de ella se desprenden los siguientes objetivos específicos:

- Conocer las estrategias que utilizan los profesores en formación del área de ciencias sociales para enfrentar la vulnerabilidad escolar dentro de sus prácticas pedagógicas.

- Identificar las fuentes de origen de las estrategias desplegadas por los profesores en formación durante sus prácticas pedagógicas.

- Develar las limitaciones que declaran encontrar los profesores en formación dentro del proceso de práctica pedagógica en un marco de vulnerabilidad escolar. 
- Caracterizar la noción de vulnerabilidad escolar de los profesores en formación enfrentados a su proceso de práctica pedagógica.

\section{METODOLOGÍA}

La finalidad de este estudio es conocer las representaciones de la docencia en contextos de vulnerabilidad que desarrollan profesores en formación de ciencias sociales, develando de esta forma sus creencias, imágenes y puntos de vista, frente al contexto que tuvieron que enfrentar, exponiendo a la vez las fuentes de origen, estrategias y limitaciones que ellos mismos describieron en el transcurso de la investigación. Por lo tanto, este estudio se enmarcó en una metodología de carácter cualitativa, debido a que este tipo de enfoque abarca la percepción de las múltiples realidades y variables fenomenológicas que inciden en el actuar de los sujetos, sin generalizar una realidad sino que más bien intentando comprender las diferentes realidades subjetivas a estudiar (Sampieri, 2010). El tipo de estudio fue exploratorio y descriptivo, dado que se busca indagar una realidad social y de describirla con el propósito de aprehender su estructura y sentido. El diseño de la investigación fue de carácter narrativo, abocándose principalmente en la recolección de datos en torno a las vivencias personales de los diferentes profesores en formación que participaron en esta investigación. Desde otra perspectiva, el estudio asume un carácter no experimental pues no se contempló la manipulación de las variables; y con alcances transeccional, en tanto la recolección de la información se llevó a cabo en un momento único.

Participan de la investigación 15 profesores en formación que, tras brindar su consentimiento informado decidieron participar y estuvieron dispuestos a ser acompañados en el proceso de práctica en contextos de vulnerabilidad. La información fue recogida vía guión de preguntas, articuladas en torno de un relato de entrevista, que asumió la modalidad de semiestructurada, permitiendo "excavar" de forma cercana, abierta y directa las percepciones personales de cada uno de ellos.

El análisis de datos, implicó la transcripción de las entrevistas, para su posterior análisis de contenido. Finalmente, el trabajo interpretativo que se realizó sobre lo expresado por los informantes en las entrevistas, devela que la principal referencia en cuanto a lo dicho por los individuos son las expresiones verbales, las cuales, una vez extraídas, dan cuenta de un contexto particular, siendo perceptibles sus postulados acerca de su realidad en estos establecimientos.

\section{RESULTADOS Y ANÁLISIS}

\section{Estrategias utilizadas por los profesores en formación en contextos de vulnerabilidad}

\subsection{Estrategias personales}

Enfrentados a contextos de vulnerabilidad, reconocen el impacto que dichos escenarios les provoca y descubren ser ellos mismos, la principal y primera de las estrategias desde la cual se ven movilizados a actuar, generando estrategias de interacción ancladas en características personales o disposiciones que buscan el encuentro, la relación y la convivencia, convencidos tempranamente de la necesidad de conocer a sus estudiantes:

"En un principio sí, me ha complicado en el sentido de que uno al estar recién comenzando quizás no tiene tanta estrategia para poder llegar a ellos (...) Pero al ir conociéndolos, al ver que al demostrarles que uno está interesado en ayudarlos se ha ido superando esta barrera”

Los profesores describían que al momento de conocer y relacionarse con los mismos estudiantes, se iban generando "relaciones humanas" que permitían una disposición distinta hacia el trabajo y el funcionamiento en el aula. 
“descubrí que era importante hacerles sentir que los consideraba, dar solución a los problemas de sus estudiantes, generar cercanía y vínculos con ellos, establecer más relaciones más humanas, preocuparse más como personas que como objetos" $\left(E . n^{\circ} 8\right)$

Este tipo de estrategia se vincula con lo planteado por Tardif (2004), que destaca que una de las características del trabajo docente es su relación con seres humanos, por lo que debe basarse en percibir sus emociones, temores, alegrías y sus propios bloqueos afectivos dentro del proceso enseñanza-aprendizaje.

La importancia de esta relación bien lo reconocen los profesores en formación, cuando señalan que el manejo del contenido - como en su caso- no es garantía suficiente de éxito en el aula.

"Si tú no logras ser un profe que tiene llegada con los cabros chicos, es imposible que vayas

a trasmitir los conocimientos que tengas, de la manera que tú quieras trasmitir” (E. $\left.n^{\circ} 10\right)$

En este sentido, al momento de relacionarse con los estudiantes, diferentes profesores establecieron que el mecanismo utilizado para lograr un "respeto" fue desarrollar una relación de empatía con los mismos estudiantes:

"La idea mía en un inicio fue eh, no sé, empatizar y sobre todo respetarlos, respetarlos. Si yo los respetaba iba a considerar que ellos me iban a respetar a mí y de esa forma lo hice y nunca fui al choque" (E. $\left.n^{\circ} 1\right)$

"Yo creo que cien por ciento empática, espero que no me juegue en contra y que siempre pueda llegar a los chiquillos (...) porque no es mucho lo años que han pasado de que yo fui alumna asi que, no hay que olvidar eso, no hay que olvidar que uno fue alumno también, se le olvida a uno de repente pero no hay que olvidarlo" $\left(E . n^{\circ} 15\right)$

En este sentido, uno de los sujetos fundamenta su acción a partir de la complejidad que caracteriza a los grupos familiares de los estudiantes

"Yo creo que es la empatía, ponerse en el lugar de que no estamos hablando con niños que tienen apoyo en su casa, de que tiene los materiales, de que los papás están preocupados no, o sea al final eso lleva a la práctica” (E. $\left.n^{\circ} 2\right)$

Son conscientes que una figura tradicional de autoridad en estos contextos corre el riesgo de generar más resistencia de parte de los estudiantes, que disposición hacia el aprendizaje.

"Me tocó estar en otras clases con otros profesores que nunca se pusieron en lugar de los alumnos sino que les gritaban y al final con ese tipo de alumnos yo lo que pude ver es que eso no funciona, o sea... tratar de imponer la autoridad... ;No!” (E. $\left.n^{\circ} 2\right)$

"El tema de eso de presentarte como ya una imagen de que manda dentro de la sala, considero que eso ya pasó, eso era para los profes de antes” $\left(E . n^{\circ} 15\right)$

La complejidad del contexto obliga a movilizar todos los recursos personales disponibles:

“Tú tienes que saber reaccionar a veces aconsejar, a veces consolar, a veces escucharlo, entonces te sales un poco del parámetro disciplinar y tienes que partir eh... ser..., ósea irte por el otro lado, como emocional y hacer muchas veces de adulto significativo" (E. $\left.n^{\circ} 14\right)$

Desde la perspectiva de Tardif (2004)

La enseñanza se asemeja mucho más a la actividad política o social, que pone en contacto a unos seres humanos con otros, que a la técnica material o a la ciencia (pág. 104)

1.2 Estrategias Metodológicas 
Por otra parte, los profesores en formación, describieron como abordaban una clase y cuáles eran las diferentes herramientas que utilizaban para motivar a este tipo de estudiantes.

Para un grupo de profesores, uno de los elementos que consideraron relevantes en estos contextos fue apostar al sentido y significatividad en la entrega de contenidos y habilidades:

"Trato de hacer el objetivo útil para mis estudiantes, el objetivo de aprendizaje, de darle una utilidad para ellos de su vida cotidiana que sirva de algo lo que están aprendiendo por eso me esfuerzo más que por la cantidad del contenido" (E. $\left.n^{\circ} 8\right)$

"A mí me daba lo mismo que ellos por ejemplo no supieran identificar un periodo del otro, pero si me importaba que ellos por ejemplo si leían un texto podían rescatar la idea principal, (...) eso era lo que me interesaba, de que ellos pudieran desarrollar habilidades más que una acumulación de contenidos" $\left(E . n^{\circ} 12\right)$

Otros identifican estrategias de acción orientadas directamente al manejo didáctico para generar aprendizaje en sus estudiantes:

“Apuesto al trabajo con guías con pocas preguntas, pero apostando siempre a desafio o tarea que representen un desafío, un sentido, generalmente acompañadas de datos curiosos que llaman la atención (E. $\left.n^{\circ} 1\right)$

“mucho trabajo interactivo que los mueva y los mantenga en movimiento (E. $\left.n^{\circ} 2\right)$

"Didáctica, hacerlos participar, porque son chiquillos muy inquietos, muy desordenados (...) o sea trata de hacerlo participes a todo para que puedan estar enfocado en lo que están” (E.

Finalmente, un grupo de profesores en formación manifestó que una de las estrategias relevante que ocuparon durante el desarrollo de su clase, ya sea para resolver problemas como para entregar el contenido, es que los alumnos puedan desarrollar la capacidad de reflexión en el aula:

"Trato que ellos reflexionen de que vayan haciendo asociaciones, de no condicionar sus respuestas, esa es como mi mayor meta, por eso voy por la reflexión” $\left(E . n^{\circ} 10\right)$

"Yo los hago reflexionar respecto a todas las situaciones del aula, las de contenido y las situaciones de indisciplina que se generan con mucha facilidad, haciéndoles ver lo que pierde cada uno de ellos y yo también en esas situaciones si las dejamos pasar. Cuesta pero considera que es necesario y tiene sentido $\left(E . n^{\circ} 14\right)$

2. Fuentes de origen de las estrategias

2.1 Práctica-Teoría

En primer lugar, un grupo de profesores señala que durante su práctica pedagógica, prima la experiencia, el consejo de los profesores y la reflexión personal para poder resolver diferentes situaciones complejas en establecimientos vulnerables.

Para ellos, el profesor se forma verdaderamente en la práctica, enfrentado a los requerimientos del aula y las demandas de los estudiantes.

"Yo creo que básicamente experiencia e intuición y también yo creo que los consejos de los profes que hemos tenido, los profes guías y también de los profesores de la Universidad, pero 
no creo que sea cien por ciento teórico (...) en el fondo tú tienes que vivirlo para aplicar la teoría para poder saber cómo es realmente" (E. $\left.n^{\circ} 14\right)$

"La Universidad no te puede entregar todo digamos, pero siento que hay algunas cosas básicas o que son muy importantes". "Pero también uno reflexiona el sentido de que uno se da cuenta de que una clase no fue buena o cuando fue buena (...) sentado, conversando con otros compañeros y ahí uno mismo pensando y viendo que cosas uno hizo bien” (E. $n^{\circ}$ )

Las citas anteriores, ponen de manifiesto el valor otorgado a los saberes que nacen de la misma práctica (saberes experienciales), quedando en segundo plano los saberes procedentes de la teoría. Paquay (2010) define esta relación a través del paradigma de "maestro artesano: el maestro de oficio puede ser considerado como alguien que sabe improvisar, o más bien como un "artesano" que sobresale en el arte de reunir los materiales disponibles y de estructurarlo en un proyecto que adquiere sentido de forma intuitiva (pág. 245)

\subsection{Teoría - Práctica}

Otro grupo de profesores reconoce en el conocimiento teórico, la fuente desde la cual se toman decisiones y se enfrentan los requerimientos del aula. En consecuencia, para ellos primero es necesario saber, para posteriormente aplicar:

"Me preocupo en mi practica de estudiar, de estudiar las etapas biológicas de mis estudiantes (...) para saber básicamente cómo reaccionar (...) la teoría te lo da la universidad po, eso te lo entregan en psicología no sé si en las metodologías en este caso" (E. $\left.n^{\circ} 8\right)$

"Me ha servido mucho lo visto en la universidad, cuando tuve la psicología del desarrollo y del aprendizaje, desde ahí he podido entender mejor a los estudiantes y sus reacciones, que es lo que más me preocupa” $\left(E . n^{\circ} 12\right)$

Desde la perspectiva de Paquay (2010) el maestro cuando conoce las bases teóricas y posteriormente las aplica en la práctica, se enmarca en un paradigma tradicional denominado "maestro ilustrado". Para convertirse en maestro experto hay que conocer antes de aplicar las bases teóricas en didáctica de la especialidad, en metodología general y en psicopedagogía.

\subsection{Equilibrio Teoría-Práctica}

En tercer lugar, dos profesores señalaron que tanto la teoría como la práctica son un complemento para desempeñarse en este tipo de contextos, sin darle prioridad a uno sobre el otro, muy por el contrario aproximándose a una comprensión más situada de la naturaleza del trabajo docente.

"Igual uso la experiencia, por lo general son patrones que se repiten en las prácticas, la experiencia sirve mucho, pero también la teoría, se equiparan, se ayudan, son complementarias" $\left(\right.$ E. $\left.n^{\circ} 7\right)$

"De todo, es todo un poco, porque somos más allá de profesores, somos seres humanos, personas integras (...) son todas validas todas las herramientas, de la casa, de la universidad, de tu intuición, tus emociones, son todas válidas" (E. n¹1)

De las citas anteriores, se evidenció que ambos informantes conjugan saberes tanto teóricos, prácticos y personales, sin darle prioridad a ninguno de ellos, sino que completándolos o integrándolos en su práctica pedagógica. Siguiendo los planteamientos de Paquay (2010) un maestro que además de considerar las bases teóricas integra los conocimientos que se generan en la práctica, se situaría en el paradigma del "practicante reflexivo", vale decir, "un estratega que no se fía únicamente de los conocimientos básicos, aunque hayan sido probados; él los actualiza periódicamente y pone a prueba otros enfoques con el fin de mejorar la eficacia de su práctica (pág. 245) 


\subsection{Divorcio Teoría-Practica}

Finalmente, un grupo de profesores señaló que no existe una vinculación clara de la teoría entregada por la Universidad con la práctica pedagógica que los interpela en los establecimientos educacionales, viéndose enfrentados a una tarea donde no es extraño guiarse más por el sentido común, su intuición y lo aprendido en el aula con los estudiantes, a la hora de hacer frente a las situaciones complejas diversas que viven a diario. Para ellos teoría y práctica son realidades opuestas.

"Fue una corazonada, instinto más que nada o un sentido valórico que se da en las casas o no sé, en la formación que, que aplique, no fue lo que me enseñaron en la Universidad (...) son pequeñas cosas que a lo mejor que a uno como profesor no le enseñan en la Universidad, sino que uno lo va aprendiendo por la experiencia” $\left(E . n^{\circ} 1\right)$

"Yo voy por el tema de la intuición pedagógica, porque eso te da libertad, libertad en el sentido de que... intuición porque son tantos los diversos problemas que suceden cachai'o situaciones conflictivas, que esta intuición pedagógica te sirve para ir adaptándote a todas... a cada uno de ellos.... No hay una ley general... ósea de acuerdo a la situación tu actúas, ósea esa es mi sensación" (E. $\left.n^{\circ} 10\right)$

$\mathrm{Al}$ momento de preguntarles a los profesores en práctica por qué tomaban ese tipo de decisiones en una situación compleja, aluden a la distancia entre las disciplinas teóricas de la Formación Inicial, y la complejidad de los contextos reales donde se desarrolla la docencia.

"Sentía que era como algo de mucha teoría, cosas que en realidad sentía que unos ramos estaban demás, entonces como que no me gustó mucho pero si cuando hice mi primera inserción porque es distinto po', estas en el colegio, sientes que si se te da el relacionarte con los alumnos" (E. $\left.n^{\circ} 2\right)$

"Yo creo que lo teórico de la Universidad en la práctica cambia demasiado, mucho, porque en la Universidad te tratan de formar para un alumno que te va a escuchar, un alumno que va a ir con ganas de aprender y en la práctica no se ve” (E. $\left.n^{\circ} 15\right)$

De las citas anteriores, se evidenció que los profesores en formación descartan la utilización de saberes teóricos, criticándolos por su alejamiento a la realidad de aula y su generalización al momento de enfrentarse a diversos contextos educativos. Por lo mismo, señalan que la intuición y la experiencia les brindan la libertad de poder desenvolverse dentro de su práctica pedagógica.

\section{Limitaciones al momento de desarrollar la práctica}

Para la mayoría de ellos, las limitaciones encontradas dentro de este contexto se asocian tanto a la carencia de herramientas y habilidades pedagógicas que no fueron adquiridas en su formación inicial, como a los espacios efectivos que proporciona el establecimiento educacional para trabajar y aprender el oficio.

\subsection{Limitaciones institucionales}

Parte de los sujetos, reconoce la presencia de profesores guías que no proporcionan el espacio necesario para desarrollarse, viéndose limitados por su condición de practicantes, y en muchos casos reducidos en su actuación a la tarea de observadores, o con una actuación muy condicionada a la observación permanente por parte del guía.

"Cuando te dicen que tienes que estar solo observando (...) es limitado porque si se ve que unos alumnos están peleando o se están diciendo cosas o garabatos con el otro alumno, ¿qué es lo que debo hacer?" $\left(E . n^{\circ} 1\right)$ 
"Si, fue una limitante el hecho de que algunos profesores no den los espacios es una limitante ya que uno está sentado mirando no más... un observante pasivo nada más” (E.

"Me vi bastante limitaba en el establecimiento, de hecho podría decir que no pude intervenir mucho, porque la profesora pensaba que el tipo de alumnos que tenía en ese curso no me iba permitir hacer una clase o alguna actividad" $\left(E . n^{\circ} 13\right)$

"Que el profesor te deje sola en la sala, o sea yo podría haber hecho miles de prácticas, pero si el profesor no te deja sola en la sala de clases yo todavía soy un estudiante" (E. $\left.n^{\circ} 6\right)$

“Cuando uno está sola en la sala, uno improvisa eh... varía el contenido, alguno lo profundizas más, otros no, en cambio cuando el profesor está tienes que prácticamente tienes que seguir toda la estructura que ya tenía preparada en la planificación y no puedes variar mucho de acuerdo a lo que se dé en la clase" $\left(E . n^{\circ} 14\right)$

Asimismo, existen profesores que si bien logran realizar el oficio de manera más frecuente, sienten la presencia "defensiva" de sus guías, generando la incomodidad respectiva:

"Esta ese miedo del profesor de que llega el practicante, que el practicante me puede quitar mi pega y el resto de los profesores se pone a la defensiva y (...) uno evita porque sabe que incomoda" (E. n $\left.{ }^{\circ}\right)$

"Me hacen sentir muy incómoda con el hecho de que los practicantes no podamos ser parte del circulo de los profesores po'(...) yo no puedo entrar a las sala de profesores si los profesores están en actividades (...) somos lo último de la cadena

(...) no podemos participar en ninguna actividad que sea (...) propias de la actividad docente (...) eso me priva de aprender porque para eso son mis prácticas” $\left(E . n^{\circ} 8\right)$

\subsection{Limitaciones derivadas de la Formación Inicial}

Dentro de las limitaciones emergen las asociadas al tema didáctico y evaluativo que se derivan de la formación inicial

"Falencias como la didáctica (...) nos falta. Si, limitan el actuar porque uno más allá que haga las horas con algo de experiencia, en su momento uno, eh... cuesta tomar ritmo, cuesta hacer algo" $\left(E . n^{\circ} 1\right)$

“No está como lo didáctico... de hecho, tenemos una asignatura o dos creo pero yo encuentro que es poco (...) el hecho tan simple de escribir bien es algo como básico y muchos de nosotros no lo hacemos (...) entonces igual es como complicado” (E. $\left.n^{\circ} 2\right)$

Por otro lado, otros profesores destacan que aparte de la carencia de conocimientos didácticos, les faltaron ramos relacionados a metodologías de la especialidad: "Siento que me faltaron ramos en lo que te dijeran a ti eh... mira, esto es un mapa conceptual (...) se hace de esta forma, se aplica para tales objetivos... eso, siento que falto ese ramo y tengo que entendido que en la metodología de la especialidad se enseña y... ¿tenemos una solamente? quedamos al debe" $\left(E . n^{\circ} 5\right)$

"Faltas en metodologías en cuanto a aprendizaje, en cuanto a didácticas con los niños yo encuentro que ahí (...) de un punto de vista (...) de lo metodológico y del aprendizaje” (E.

Por otro lado, un números importante de los practicantes, advierte la escasa preparación en torno a los contextos de inserción y particularmente los desafios que el trabajo en y con vulnerabilidad, pues tensiona de manera particular la naturaleza del trabajo a realizar. 
“Como lidiar con situaciones extremas por ejemplo, aquí nunca nos preparan para eso, aquí nos preparan para un modelo casi estándar de educación... yo creo que ahí debiéramos trabajar... con problemas reales" $\left(E . n^{\circ} 3\right)$

Por lo mismo, otro profesor destaca que por desconocer la metodología y una didáctica adaptada a contextos vulnerables, finalmente los estudiantes reaccionan con rechazo:

"Uno bueno por desconocer trata de aplicar actividades, metodologías y obviamente los alumnos no están acostumbrado a eso poh, un colegio vulnerable están acostumbrado a de repente que los gritoneen, a que lo anoten, a que lo saquen de la sala y de repente cuando uno quiere ser distinto (...) obviamente ellos reaccionan con rechazo ante eso y la limitación es esa” $\left(E . n^{\circ} 12\right)$

\subsection{Limitaciones personales}

Dentro de la investigación, parte de los informantes describieron una serie de limitaciones derivadas de una falta de confianza en su trabajo, derivado de los temores que provocan los contextos y los actores del aula

"Consideré que me faltaba mucho y dije no es lo que me esperaba, si bien sabía que no me iba a resultar bien al principio me esperaba más... eh también uno tiene un ideal de pedagogía y se da cuenta que no es tan así, eh... no se trató de generar empatía de relacionarme con los estudiantes" $\left(E . n^{\circ}\right)$

Son conscientes además, que llegan a estos establecimientos sin disponer del conocimiento necesario de estos contextos, ni de las herramientas suficientes para actuar en ellos. Además de no tener en muchos casos, una clara conciencia de este tipo de realidades

"Yo creo dentro de mi autocritica (...) cuando yo entré acá venía con la concepción del profesor que habla y los alumnos escuchan" $\left(E . n^{\circ} 7\right)$

Una vez enfrentados al contexto, comienzan a constatar una serie de limitaciones personales, que reconfiguran todas sus creencias respecto al trabajo docente, generando en muchos casos obstáculos emocionales:

"Por ejemplo a mí lo que siempre me ha costado es el manejo de grupo, creo que soy un poco, no sé si empático o me cuesta ser mano dura, porque creo que mi percepción es otra sobre eso" $\left(E . n^{\circ}\right)$

"Cuando empecé a analizar y empecé a reflexionar me di cuenta que (...) en ese ámbito tengo que desarrollar unas capacidades que son como las de un líder, que el curso pueda seguirme (...) pero un niño que viene de un contexto vulnerable es distinto no puedo tratarlo igual" $\left(E . n^{\circ 9}\right)$

\section{El concepto de vulnerabilidad en profesores en práctica}

Los entrevistados reconocen la presencia de la vulnerabilidad en el trabajo docente, en la relación con los estudiantes y en las posibilidades de aprendizaje. Reconocen, sentirse absorbidos por los problemas que conllevaría la vulnerabilidad,

"Tienen muchos problemas emocionales con los niños, de naturaleza afectiva, de conducta que eso al final te afecta y sin querer eso también te lo llevas al ámbito personal, ósea a tu casa de repente, te puedes deprimir y eso po'”. (E. $\left.n^{\circ} 3\right)$

"No resulta fácil lidiar con alumnos a los cuales no le interesa mucho aprender, sus formas de relación, el uso del lenguaje, en fin, no es fácil! (E. no4) 
También en estos diálogos con los futuros docentes afloraron limitantes relacionadas con la vulnerabilidad; eventos, situaciones, incapacidades, momentos que llevaron al docente a sentir una barrera. Por ejemplo, se encontraron con barreras comunicacionales, con alumnos confundidos puesto que su entorno y familia tienen diálogos poco adecuados para un niño, lo que provocaría que estos asimilen estos diálogos como algo normal.

"No es algo que uno le dice estás diciendo un garabato, ellos responden con un que dije profesor o que huea dije lo tienen tan asimilado como propio (...) No diga eh... garabato, diga que dice aquí. Pero profesor no dije eso, no digo garabatos. Entonces es como una confusión entonces el alumno eh, como dice el director la parte de formación es más importante que la parte de contenido. Ese fue como un consejo que me dio él” (E. $\left.{ }^{\circ} 1\right)$

Por otra parte, se encuentran con una etapa biológica compleja, que es la adolescencia, en donde cualquier estímulo puede tener reacciones inusitadas e insospechadas, con el agravante de lo que significa sumar otra variable: la condición de vulnerabilidad

“También uno puede ver las situaciones de vulnerabilidad en la agresividad de los niños porque...todo esto esa irritación, esa confusión, esa agitación misma de la época o la etapa de su vida que están viviendo lo demuestran en el colegio...” (E. $\left.n^{\circ} 2\right)$

"Porque cualquier cosa que tú puedas decirle al alumno como para llamarle la atención puede ser tomado como un insulto, como bullyng o como abuso de poder, entonces es complicado, los profes están... están.... están como complicado, sobrepasado y aburrido a la vez" $\left(E . n^{\circ} 15\right)$

"La vulnerabilidad se manifiesta en diversas situaciones y de distintas maneras, parte de la poca capacidad de expresarse del alumno dentro de la sala y que por lo general es por vergüenza y se va notando eso por el volumen de la voz, por las posiciones de la manos, como que se tapan, como que se esconden" (E. $\left.n^{\circ} 10\right)$

"La vida de los niños eh... te asombra, en el sentido de que ellos tienen costumbres que son o que difieren totalmente a las tuyas, por lo tanto uno tiene que tener tino, tiene que tener mucho cuidado cuando trata cierto temas" $\left(E . n^{\circ} 11\right)$

“De partida en colegio vulnerable no podi' usar termino demasiado rebuscado por decirlo de alguna manera, eh... hablar con un lenguaje que fuera un poco más cercano y más entendible para al alumno era la base" (E. $\left.n^{\circ} 12\right)$

A la hora de preguntarse el porqué de estas barreras que impone la vulnerabilidad, la motivación del estudiante aparece como la principal respuesta, como lo expresa el siguiente entrevistado:

"La vulnerabilidad afecta motivación que muestran los alumnos (...) la motivación no venía de la casa y tampoco se les daba en el colegio entonces el niño andaba siempre al paso', entonces la vulnerabilidad para mí son todos los elementos que condicionan la motivación y condiciones del alumno para que pueda aprender” $\left(E . n^{\circ} 9\right)$

Esta falta de motivación se evidenciaría en un desinterés y predisposición negativa por parte de los sujetos a la hora de enfrentarse a la clase, como lo expresa el siguiente entrevistado.

"En el poco interés de los estudiantes de participar de la clase a mí eso me llamó la atención, más que en realidad la nota me llama la atención el poco interés, la predisposición con el alumno se enfrentaba a la clase (...) molestos porque tu cuando vez que alguien no quiere poner atención a algo es por una molestia, es por algo que al alumno no le agrada” (E. $n \circ 8)$

Situación que se ve agravada por la complejidad que presenta el núcleo familiar y las expectativas que tienen para sus hijos: 
"Les dicen: para que vas a hacer esto... para que vas estudiar... para que vas a salir adelante... y por qué... si aquí no lo vas a necesitar" (E. $\left.n^{\circ} 6\right)$

Pero también por la capacidad de respuesta que tiene el establecimiento para generar situaciones facilitadoras de aprendizaje:

"Si, si yo creo que eh, pasa por ahí pasa por una despreocupación de la calidad del aprendizaje de los estudiantes, de generar estrategias y metodologías que realmente sirvan y que se preocupen de que alumno aprenda” (E. n' 8$)$

"El profesor también es vulnerable si no es capaz también de afrontar una situación y el estudiante es vulnerable si no le orienta quizás a enfrentar una situación, entonces la vulnerabilidad es un concepto que raya en la subjetividad" $\left(E . n^{\circ} 11\right)$

Este no afrontar las situaciones, tendría un origen en los estereotipos y prejuicios que el profesor puede tener con estos entornos de vulnerabilidad, como lo expresan los siguientes docente en formación:

"Otro punto que se logra ver es que se deben sacar los estereotipos y la predisposición antes de enfrentar estos contextos y realidades tan ajenas" $\left(E . n^{\circ} 11\right)$

"Yo creo que debemos sacarnos esos estereotipos de la mentes y comenzar a entender que en cualquier contexto donde nos encontremos, nos vamos a encontrar trabajando con personas, con niños, con jóvenes y que obviamente tienen la misma necesidad de aprender que cualquier otro" $\left(E . n^{\circ} 14\right)$

4.1 Situaciones en relación a vulnerabilidad.

Durante los procesos de práctica profesional los futuros docentes nos relataron diversas situaciones que fueron marcando su estadía en estos entornos vulnerables, describiendo experiencias que consideraban "crudas", asociadas a la importancia que puede asignarle un niño al hecho de tener acceso a una alimentación diferente, como lo expresa el siguiente entrevistado:

"Varios niños estaban contentos no tan solo por el viaje sino porque...porque también tenían la posibilidad de comer pan con queso y jamón y tomar bebida, algo taaan' común que para cualquiera de nosotros, eh... comer un pan con queso y tomar bebida (...) para ellos era algo nuevo, algo lujoso por decirlo de alguna forma, algo que era pocas veces, podían haber tenido acceso a este tipo de alimento" $\left(E . n^{\circ} 1\right)$

Se enfrentaron a situaciones impensadas para la edad de un niño de enseñanza básica, como lo expresó el siguiente entrevistado:

"Me tocó ver la prueba de un niño, de un alumno de séptimo que me empezó a describir armas, entonces dije ¿ah tú conoces de armas?, si profesor él me dijo y me empezó a hablar de 9 largo, 9 corto que eran no se... tipos de armas y dije ¿pero cómo sabes tú de armas? $Y$ nooo profe aquí los chiquillos me decían... en relación a lo del barrio y pero me dijo que la que más le gusta es como un fusil de guerra dijo, ¿Cuál fusil de guerra? ... uno que ocupan los rusos me dijo, ¿el fusil Ak47? le dije, sipo me dijo, como vas a saber le dije si al menos tú tienes no se po, 11 años tiene un niño de séptimo...”. (E. n'1)

Realidades fuertes donde es preciso tomar decisiones acertadas y adecuadas, si lo que se persigue es el bienestar y el aprendizaje de los estudiantes:

"Un caso concreto, llegué un día a clases y una alumna se quedó dormida y obviamente la profesora realizaba su clase normal, yo me acerqué a ella para ver si se sentía mal o algo así, claro que le había pasado en una de esa se sentía mal y podría haber salido de la sala y me dice que tenía sueño porque la noche anterior no había dormido nada poh y le pregunté por 
qué no había dormido nada, "Bueno, porque anoche pasé toda la noche en el poli tratando de que me atendieran porque mi hermano chico tenía neumonía y mi mamá trabaja de noche y la única persona que podía llevarla al consultorio en este caso era yo po y no me atendieron

sino hasta la 5 de la mañana y por eso tengo sueño". Entonces ahí uno se da cuenta que tenemos un rol, una importancia que va más allá de entregar el contenido y me cuestiono si tenemos las herramientas para afrontar esas situaciones" $\left(E . n^{\circ} 12\right)$

También aparece en estas situaciones, la peligrosidad asociada principalmente a la delincuencia, como lo expresa el siguiente entrevistado.

"En la práctica anterior tuve inconveniente un día que un alumno preguntó por las zapatillas

(...) me preguntó cuánto calzaba y como que... el profesor me miró, el profe guía y me hizo así como el gesto así como que evitara un tema no sé. Y era, porque claro le habían dicho el mismo comentario a un practicante de lenguaje sobre el computador, que le había gustado el computador y lo pillaron afuera y se lo quitaron” $\left(E . n^{\circ} 15\right)$

4.2 Fuentes de origen de la vulnerabilidad.

4.2.1 Vulnerabilidad desde el núcleo - familiar

Algunos entrevistados reconocen en la despreocupación de la familia y la economía del grupo familiar, el principal foco de vulnerabilidad para los niños en sus posibilidades de aprendizaje y en lo complejo que se torna el trabajo de los profesores

"No estamos hablando con niños que tienen apoyo en su casa, los papás están bien poco preocupados" $\left(E . n^{\circ}\right)$

"Si uno va a pedir un material, que este no sea muy caro, muy dificil de acceder a ellos" (E.

"Me encontré con una realidad donde los alumnos algunos no tenían cuaderno y no porque no quisieran o porque fueran el típico alumno más despistado que obviamente llegaba sin materiales, sino porque los padres no tenían los recursos para comprarle a sus hijos...” (E.

“No todos de repente tienen los materiales cuando uno quiere trabajar" (E. $\left.n^{\circ} 15\right)$

A la hora de ahondar un poco más, nos encontramos con problemas aún mayores, que nacen desde el núcleo familiar, que ya no solo se relacionarían con una despreocupación de los deberes escolares por parte del núcleo familiar sino que, una despreocupación completa por la vida de estos niños.

"El hecho del aseo personal de los niños, zapatos sucios, no tomaban desayuno, el colegio paraba, paraba la hora de clases a las 9, se iba al comedor, tomaban desayuno, después volvían aunque perdiesen media hora de clases pero el alumno tenía un vaso de leche o un té con un pan con mantequilla aunque sea que, que era el alimento que era el, el único alimento que consumían durante la mañana, entonces eso como que fue impactante" $\left(E . n^{\circ} 1\right)$

“Un descuido de la familia que se ve reflejado cuando el alumno (...) es fuerte y más en niños que uno espera que los papás no se po, tengan el tiempo en la mañana para por ultimo lavarles la cara, no se eh... que se limpien las nariz, las manos, oh, oh peinarlos" (E. $\left.n^{\circ} 1\right)$

"Me tocó muchas veces ver alumnos que llegaban con la ropa rota, que no había tomado desayuno, que querían quedarse hasta más tarde porque querían almorzar, entonces es ahí cuando uno vive contextos difíciles, cuando uno se da cuenta de que el contexto en que se desenvuelven estos niños es tan complejo, donde no existe el apoyo de los padres" (E. $\left.n^{\circ} 13\right)$ 
Pues bien el colegio y a no solo sería un lugar donde se produce el proceso de enseñanza aprendizaje, pero ¿Cómo se explica que exista tal nivel de despreocupación por sus materiales, vestimenta y la higiene adecuada?, ¿Qué pasa realmente en las casas?, muchos

núcleos familiares disfuncionales con escaso apoyo afectivo, padres con una gran carga laboral y también con muchos problemas como alcoholismo y drogadicción. El trabajo en aula se hace bien difícil, pues es tanto lo que hay que mejorar y ni siquiera muchas veces se desea cambiarlo...” $\left(E . n^{\circ} 1\right)$

"Los niños no tienen ni la base de apoyo de la familia y eso es lo que complica las cosas (...) el hecho de que no tengan una familia para apoyarlos cualquiera sea la conformación de esta familia, alguien apoyándolos sólidamente atrás... esto complica la situación” (E. $\left.n^{\circ} 4\right)$

“Papás separados... mamas eh... que trabajan... trabajan mucho... a veces ellos se quedan solamente con su mamá... y no tienen como a nadie en la casa que los dirige... o como diría un profesor... eh les tire las rienda... hiciste la tarea, donde está tu tarea...”. (E. $\left.n^{\circ} 6\right)$

“Los niños que ingresan ahí, en el sentido de que aparte de que tengan problemas económicos en su casa... tienen mucho problemas de afectividad” (E. $\left.n^{\circ} 14\right)$

\subsubsection{Contexto de vulnerabilidad externo-social}

Algunos entrevistados reconocen como fuente de origen de la vulnerabilidad el contexto social que rodea al sujeto, este contexto lo condicionaría en su actuar y este se haría más evidente al observar la convivencia entre ellos y sus reacciones al enfrentar la clase, como lo expresan los siguientes entrevistados.

"El ambiente podría ser un poco, se nota porque por ejemplo no sé, en los recreos podríamos decir que la convivencia en sí es complicada con los alumnos, porque el respeto entre los pares se perdido mucho" $\left(E . n^{\circ} 2\right)$

“Ahí uno nota que hay como un tema actitudinal de parte de ellos que es bastante débil... No sé a qué se deberá eso, eso ya te demuestra cómo es su entorno" (E. $\left.n^{\circ} 10\right)$

"Yo creo que eso dicta mucho del contexto en que uno puede trabajar que son distintos los colegios, cuando son distintas realidades (...) por eso te digo, los colegios de por si los estudiantes son complicados porque tienen problemas" $\left(E . n^{\circ} 14\right)$

Estos contextos de origen cargan consigo otras problemáticas y tensiones.

“Una cosa es por el ambiente que se da... de no tener lo suficiente... bueno por ejemplo casi siempre la gente vulnerable... ya sea económica o culturalmente... viven en poblaciones en las cuales se generan no se po... los índices más altos de robos, delincuencia, drogadicción, Todas esas cosas, generan que estos niños no vean más allá” $\left(E . n^{\circ} 6\right)$

"Vivan en un entorno que esté ligado con la drogadicción verdad, o con la delincuencia, donde ellos vean esas prácticas constantes, también entra en un tema de vulnerabilidad porque, si tu creces en un ambiente donde esas cosas se te hagan habituales y normales" (E. $\left.n^{\circ} 10\right)$

Estos mismos entornos vulnerables influirían de gran forma en los sujetos, serían un flagelo constante del cual deben cuidarse, y para los cuales el liceo deberían prepararlo, ayudando a generar condiciones o mecanismos protectores.

"Niños que salían de ahí... después seguramente me decía el profe van a que estarían en la cárcel de hecho hay muchos ya en la cárcel... unos supo que se lo llevo la PDI que allanaron 
su casa que encontraron marihuana droga que se yo... entonces o que los pillaron portando armas..." (E. $\left.n^{\circ} 6\right)$

"Ellos me cuentan su realidad donde viven me he dado cuenta que son vulnerables por ejemplo, hay una gran tasa de niñas embarazadas" $\left(E . n^{\circ} 9\right)$

\subsection{Conceptualización de establecimientos vulnerables.}

Las imágenes que construyen de los establecimientos vulnerables es reconocido en un crisol de representaciones, tales como:

"Un colegio vulnerable de ciudad es completamente diferente pues (...) por lo que se ha venido viendo estos años, ahora yo no sé qué podría pasar en colegios de clase alta verdad... pero son familias disfuncionales en el sentido de que no tienen el apoyo necesario, (...) no

tienen el apoyo necesario culturalmente de los padres para poder tener otras perspectiva frente a la vida, ya sea de profesión... ya sea eh... del comportamiento, actitudes... frente a los profesores... frente al contenido... frente a la valoración de lo que se le está enseñando porque generalmente los apoderados de colegios vulnerables son cómo muy al choque'(...) no miran porque el profesor está haciendo algo, no valoran el aprendizaje” (E. $\left.n{ }^{\circ}\right)$

Para otros, el colegio vulnerable representaría lo malo de nuestra sociedad, sería el punto de ebullición de nuestros malos hábitos y trasgresiones a las leyes establecidas, como lo expresa el siguiente entrevistado:

"El colegio vulnerable es aquel que representa lo malo de la sociedad. Cuando hablamos que una sociedad hay problemas de drogadicción, hay problemas de alcoholismo, hay problemas de no se po... de embarazo adolescente, problemas de violencia intrafamiliar, etc.... todo aquello se acumula en el problema está en el colegio" $\left(E . n^{\circ} 1\right)$

Están aquellos que consideran que, en un entorno negativo, el colegio no tiene opciones de asegurar sus objetivos y está destinado a la vulnerabilidad, como lo expresa el siguiente entrevistado.

“Un establecimiento de carácter vulnerable está condicionado por el entorno más que nada, porque el entorno de esa población... por la población en que está inserto (...) en una realidad de ese tipo yo consideraría eso más influyente que cualquier otra cosa, más que el ingreso económico de las familias...” (E. $\left.n^{\circ} 3\right)$

Otras representaciones asocian los establecimientos vulnerables a problemas de masificación y pérdida de responsabilidad

"Por lo general un establecimiento vulnerable es municipal o particular subvencionado con una cantidad alta de estudiantes una alta matricula, eh... por lo que me ha tocado a mí, por lo general de escasos recursos, una familia monoparental o solamente vive con los abuelos, $o$ con un familiar que no son sus padres, hay ausencia de los tutores o apoderas, tienen mucho tiempo solos, también me ha tocado ver, problemas de drogadicción de violencia intrafamiliar

(...) como que los van a entregar a los colegios y háganse cargo de ellos, eso para mí es un colegio vulnerable" $\left(E . n^{\circ}\right.$ )

"Un establecimiento vulnerable más allá de la infraestructura, creo que radica su vulnerabilidad primero al no tener docentes, un cuerpo docente que necesariamente se adapte a las necesidades de los estudiantes, eso es un colegio vulnerable” (E. $\left.n^{\circ} 15\right)$

"Un colegio vulnerable está por las condiciones en que los profesores resuelven los distintos conflictos escolares, eso es un colegio vulnerable" $\left(E . n^{\circ} 11\right)$ 


\title{
"Ahí resulta difícil saber, porque hay algunos apoderados que se van contra el profesor (...) difícil porque nadie, nadie se atreve a trabajar con ellos y si se trabaja, se trabaja con formularios y se acaba" $\left(E . n^{\circ} 3\right)$
}

\author{
"Los apoderados de colegios vulnerables son cómo muy al choque'....como que si le hacen \\ algo a su hijo solo miran por ellos...por la situación presente... pero no miran porque el \\ profesor está haciendo algo... sino que no valoran el aprendizaje...” (E. $\left.n^{\circ} 6\right)$
}

Por otro lado, también algunos docentes en formación son enfáticos al plantear que no se debe caer en la generalización y en el prejuicio de los sujetos que asisten a estos establecimientos, como lo expresa el siguiente entrevistado:

\section{"Un colegio vulnerable no quiere decir que los alumnos no tengan inteligencia, o que el niño sea en pocas palabras más deficiente, si no que según la realidad de cada alumno es su vulnerabilidad" (E. $\left.n^{\circ} 9\right)$}

\section{A MODO DE CIERRE}

Enfrentado a los procesos de práctica y a la necesidad de responder al requerimientos que le plantean los actores (estudiantes, profesores guías y familias) y los contextos (vulnerabilidad, exclusión social, marginación), los profesores en formación inician un despertar a la conciencia (de una incompetencia inconsciente a una competencia consciente) de la complejidad insospechada del oficio, comenzando un intenso proceso de adaptación primero y aprendizaje luego que le ha de permitir sobrevivir a "la multiplicidad de tarea que supone el rol docente; a la diversidad de contextos en que estas tareas han de desempeñarse; la complejidad misma del proceso pedagógico; y particularmente a la implicación personal y el posicionamiento ético que exige la tarea docente. Aspectos que se tornan particularmente intensos en contextos de vulnerabilidad, pues estos contextos tensionan la profundidad y consistencia de la formación inicial y la capacidad de ésta para responder a los requerimientos de la realidad, con una práctica donde los dispositivos técnicos enseñados en la universidad no logran permear y sortear con el éxito esperado la sorpresa permanente que depara el contexto y los actores. Desde este punto de vista procuran perseverar, sin embargo, se enfrentan a la tentación de creer que finalmente la teoría y la práctica constituyen realidades opuestas, y con ello a rodear la tarea de intuición o sentido común.

Consideran que lo visto durante sus procesos de práctica y la realidad dinámica y compleja en la cual están insertos, demanda posicionamientos, recursos, herramientas y actuaciones que la institución formadora no logra proveer, abriendo importantes espacios para tensionar el contenido, foco y finalidad de la formación, a la cual se reclama estar en sintonía y ligazón con la realidad, asegurando una relación dialógica teoría - práctica, que permitan responder a la vulnerabilidad creciente de los contextos donde se desarrolla la profesión, el trabajo docente. Pues "las formaciones basadas únicamente en conceptos teóricos, sin referencia a la realidad, impiden que el futuro maestro encuentre más tarde estos conceptos en el terreno práctico. Se produce entonces un desfasaje entre una formación académica más bien inservible y una práctica intuitiva que puede resolver los imprevistos y problemas circunstanciales pero nos da la impresión de un eterno comienzo (Paquay et al, 2010: 105). Cuando lo que se busca es la profesionalización, estas cuestiones necesitan ser atendidas.

También emergen de la investigación, la necesidad de atender al carácter evolutivo del proceso de aprender a enseñar, mediado fuertemente por el componente personal presente en la tarea docente. En ese sentido es preciso articular una formación que permita tensionar los obstáculos epistemológicos, las creencias y concepciones de enseñanza y aprendizaje internalizadas; y los bloqueos emocionales que suponen los contextos de inserción. Respecto a los obstáculos epistemológicos, se precisa una formación inicial de profesores que permita articular la teoría y 
la práctica, de tal manera que los futuros docentes logren identificar los marcos de referencia que subyacen a la acción. En cuanto a las creencias y concepciones internalizadas se requiere hacer esfuerzos conscientes que permitan a los futuros profesores comprender el carácter procesual e implicante que representa la docencia. Finalmente, cuando se trata de enfrentar la complejidad y diversidad de contextos, es preciso trabajar en la superación de los bloqueos emocionales que los tienden a atrapar o encastillar a formas de actuación que no se corresponden con las necesidades de los estudiantes y sus contextos socioculturales.

Dentro de los desafíos planteados por los contextos de vulnerabilidad, los entrevistados son conscientes del influjo condicionador que genera el entorno social en el cual se desenvuelve el estudiante, pues tal cual lo plantea el PNUD, las barreras sociales limitan las oportunidades de las personas. ... en esferas como la educación y la salud, les resulta más difícil llevar las vidas que desean. Las barreras sociales, así como otras formas de exclusión, pueden restringir sus opciones. En conjunto, las capacidades limitadas y las oportunidades restringidas les impiden lidiar con las amenazas (PNUD H. D., 2014: 1). Los territorios escolares en contextos de vulnerabilidad comienzan a adquirir una creciente complejidad.

\section{BIBLIOGRAFÍA}

1. ÁVALOS, B. (2003). La Formación Docente Inicial en Chile. Santiago: Mineduc.

2. CISTERNAS, T. (2011). La investigación sobre formación docente en Chile. Territorios explorados e inexplorados. Calidad en la educación (35), 131-164.

3. DAVINI, M. C. (1995). Formación docente en cuestión: Política y pedagogía. Buenos Aires: Paidós.

4. DAY, C. (1999). Developing Teachers: The Challenges of Lifelong Learning. New York: Falmer Press.

5. DAY, C. (2006). Pasión por enseñar. La identidad personal y profesional del docente y sus valores. Madrid: Narcea.

6. DELORS, J. (1996). La educación encierra un tesoro. Santillana: Ediciones Unesco

7. DIKER, G. Y TERIGI, F. (1997). La formación de maestros y profesores: Hoja de ruta. México: Paidós.

8. GARCÍA - HUIDOBRO, J. FALABELLA, A. (2013). Los fines de la educación. Santiago: Ediciones UC.

9. HARGREAVES, A. (1998). Profesorado, cultura y postmodernidad. Morata: Madrid.

10. IMBERNÓN, F. (2001). Formación docente y profesional. Sao Paulo: Cortez.

11. KORTHAGEN, F. A., LOUGHRAN, J., \& RUSSELL, T. (2006). Developing fundamental principles for teacher education programs and practices. Teaching \& Teacher Education, 22(8), 1020-1041. 
12. LABRA, P. (2011). Construcción de conocimiento profesional docente: el caso de la formación en la práctica. Tesis para optar al Grado Académico de Doctor en Educación. Universidad Academia de Humanismo Cristiano.

13. LATORRE, M. (2006). Nuevas miradas, viejos problemas: las relaciones entre formación inicial y ejercicio profesional docente. Foro Educacional (10), 41-63.

14. MARCELO, C. ET AL. (2001). La función docente. Madrid: Editorial Síntesis.

15. PAQUAY, L. et al. (2010). La formación profesional del maestro. Ciudad de México: CFE.

16. PNUD, H. D. (2014). Informe sobre Desarrollo Humano 2014. New York, NY 10017, USA: PBM Graphics.

17. SAMPIERI, R. (2010). Metodología de la investigación (Quinta ed.). Ciudad de México : Mc Graw Hill

18. SAYAGO, Z. (2006). Las prácticas profesionales en la formación docente: hacia un nuevo diario de ruta. Caracas: Universidad Rovira.

19. SCHÖN, D.A. (2010). La formación de profesionales reflexivos: Hacia un nuevo diseño de la enseñanza y el aprendizaje en las profesiones. México: Paidós.

20. SCHÖN, D.A. (1987). Educating the Reflective Practitioner. San Francisco: Jossey-Bass Publisher.

21. SCHÖN, D.A. (1998). El profesional reflexivo. Cómo piensan los profesores cuando actúan. Barcelona: Paidós.

22. TARDIF, M. (2004). Los saberes del docente y su desarrollo profesional. Madrid: Narcea.

23. TENTI, E. (2007). Consideraciones sociológicas sobre profesionalización docente. Educ. Soc., 28 (99), 335-353. 